\title{
Avaliar a gestão social na governança territorial: bricolagem, aprendizagem e hibridação na construção do Índice de Gestão Social (IGS)
}

\author{
Marc Piraux \\ Cirad (Centro de cooperação internacional em pesquisa agronômica para o \\ desenvolvimento) - Montpellier - France \\ ORCID: 0000-0001-6549-2614 \\ Mireya E. Valencia Perafán \\ Universidade de Brasília - Brasília - DF-Brasil \\ ORCID: 0000-0003-0236-9154 \\ Marcio Caniello \\ Universidade Federal de Campina Grande - Campina Grande - Paraíba - Brasil \\ ORCID: 0000-0003-2765-9393 \\ Betty Nogueira Rocha \\ Universidade Federal Rural do Rio de Janeiro - Rio de Janeiro - RJ - Brasil \\ ORCID: 0000-0001-6606-8970
}

\begin{abstract}
Resumo
Entre 2003 e 2016, o governo federal brasileiro implementou o Programa Nacional de Desenvolvimento Sustentável dos Territórios Rurais (PRONAT), cuja governança se processava em colegiados participativos paritários formados pelos atores sociais, suas organizações e representantes governamentais. A gestão social constituiu o marco orientador do programa e o ciclo de gestão social buscava organizar os processos de participação, coordenação, gestão e controle social das políticas públicas pelos atores territoriais. O Ministério do Desenvolvimento Agrário começou a desenhar o seu sistema de monitoramento e avaliação em 2007. Para isso, equipes de pesquisadores de diversas universidades públicas do país foram mobilizadas. A avaliação da gestão social e seus indicadores concretos foram desenvolvidos em dois ciclos de monitoramento e avaliação, configurando-se como um processo descentralizado por meio de um índice composto pelos diversos indicadores relevantes teórica e metodologicamente, enfeixados no Índice de Gestão Social (ICS). Este artigo tem como objetivos: (i) discutir os referencias teóricos que orientaram a construção do IGS, (ii) apresentar a trajetória da metodologia de avaliação e dos sistemas de monitoramento e avaliação associados e (iii) caracterizar as dimensões do índice. Ensinamentos são tirados quanto ao processo de construção do IGS que privilegiou a bricolagem, a aprendizagem e a hibridação.
\end{abstract}

Palavras-chave: Governança territorial. Avaliação. Gestão social. Desenvolvimento territorial. Brasil. 


\section{Assess social management in territorial governance: tinkering, learning and hybridization in the construction of the Social Management Index (IGS)}

\section{Abstract}

Between 2003 and 2016, the Brazilian federal government implemented the National Program for the Sustainable Development of Rural Territories (PRONAT), whose governance took place in joint participatory colleges formed by social actors, their organizations and government representatives. Social management constituted the guiding framework of the program and the social management cycle sought to organize the processes of participation, coordination, management and social control of public policies by territorial actors. The Ministry of Agrarian Development began to design its monitoring and evaluation system in 2007. For this purpose, it mobilized teams of researchers from several public universities in the country. The evaluation of social management and its concrete indicators in two cycles of monitoring and evaluation, configuring itself as a decentralized process through an index composed of the several relevant indicators theoretically and methodologically, embedded in the Social Management Index (ICS). This paper aims to: (i) discuss the theoretical references that guided the construction of the IGS, ii) present the trajectory of the evaluation methodology and the associated monitoring and evaluation systems and iii) characterize the dimensions of the index. Lessons are given about construction process that favoured tinkering, learning and hybridization.

Keywords: Territorial governance. Evaluation. Social management. Territorial development. Brazil.

\section{Evaluar la gestión social en la gobernanza territorial: bricolaje, aprendizaje e hibridación en la construcción del Índice de Gestión Social (IGS)}

\section{Resumen}

Entre 2003 y 2016, el gobierno federal brasileño implementó el Programa Nacional para el Desarrollo Sostenible de los Territorios Rurales (PRONAT), cuya gobernanza se llevó a cabo en colegiados participativos paritarios formados por actores sociales, sus organizaciones y representantes gubernamentales. La gestión social constituyó el marco regulatorio del programa y el ciclo de gestión social buscó organizar los procesos de participación, coordinación, gestión y control social de las políticas públicas por parte de los actores territoriales. El Ministerio de Desarrollo Agrario comenzó a diseñar su sistema de monitoreo y evaluación en 2007. Para este propósito, se movilizaron equipos de investigadores de varias universidades públicas del país. La evaluación de la gestión social y sus indicadores concretos se desarrollaron en dos ciclos de monitoreo y evaluación, configurándose como un proceso descentralizado a través de un índice compuesto por varios indicadores relevantes teórica y metodológicamente, integrados en el Índice de Gestión Social (ICS). EI objetivo de este trabajo es: (i) discutir las referencias teóricas que guiaron la construcción del IGS, ii) presentar la trayectoria de la metodología de evaluación y los sistemas de monitoreo y evaluación asociados y iii) caracterizar las dimensiones del índice. Enseñanzas son recorridas sobre el proceso de construcción del IGS que favoreció el bricolaje, el aprendizaje y la hibridación.

Palabras clave: Gobernanza territorial. Evaluación. Gestión social. Desarrollo territorial. Brasil. 


\section{Introdução}

A Constituição Federal de 1988 estabeleceu um ethos participativo para a governança das políticas públicas no Brasil ao institucionalizar princípios da chamada "democracia direta" (Bobbio, 2000) em seu texto. O objetivo era promover a equidade e a justiça social ao se otimizar o desempenho das instituições públicas e a eficiência de suas políticas e ações por meio do "controle social" (Mannheim, 1971, p. 178; Carvalho, 1995, p. 8) exercido pela população. Essa "inovação institucional participativa" (Paula e Keinert, 2016) consolidou-se de tal maneira que, ela mesma, chegou a ser instituída como política pública através do Decreto $n^{\circ} 8.243 / 2014$, que criou a Política Nacional de Participação Social (PNPS), entretanto revogada pelo governo Bolsonaro.

O Programa Nacional de Desenvolvimento Sustentável de Territórios Rurais (PRONAT), instituído em 2003 e executado pela Secretaria de Desenvolvimento Territorial (SDT) do Ministério do Desenvolvimento Agrário (MDA), foi concebido no âmbito desse Zeitgeist. O Programa era centrado numa governança territorial inovadora desenvolvida por "colegiados" ou "fóruns" paritários, a qual tinha como característica diferenciadora o "ciclo de gestão social” (Brasil, 2009), com objetivo de organizar os processos de participação, coordenação, gestão e controle social das políticas públicas pelos atores territoriais. O PRONAT atingiu uma dimensão bastante significativa em termos espaciais, temporais, de investimento público, mobilização social e melhoria das condições de vida das populações envolvidas (Caniello, 2016).

Em resposta ao marco orientador do enfoque territorial para o desenvolvimento rural, o Programa foi estruturado em quatro macroprocessos: (i) articulação de políticas públicas; (ii) fortalecimento das redes sociais de cooperação; (iii) dinamização econômica e (iv) fortalecimento da gestão social (Brasil, 2005b). O ponto de partida que permeia cada um desses macroprocessos é a compreensão do território como um espaço socialmente construído no qual ações públicas para o seu desenvolvimento deverão, necessariamente, incentivar a integração de espaços, atores sociais, agentes, mercados e políticas públicas (Brasil, 2005a). No entanto, o fortalecimento da gestão social é o macroprocesso de entrada nos territórios e visa promover a conformação de coletividades representativas da diversidade de atores e interesses presentes naquele espaço social. O propósito dessa priorização é favorecer a concertação social em direção à dinamização econômica com diminuição das desigualdades e conservação dos recursos naturais.

Ao longo desse processo foram homologados 243 Territórios Rurais $^{1}$ no Brasil. Em sua forma final, o PRONAT abrangeu uma área de $6.474 .410 \mathrm{Km}^{2}$ (76\% do território nacional), reunindo 3.653 municípios (65,58\% do total do país), com 76,7 milhões de habitantes, sendo 22,5 milhões de habitantes da zona rural $(75,5 \% \mathrm{da}$ população rural), 3.513.414 estabelecimentos da Agricultura Familiar (80\%), 10.114.982 pessoas ocupadas na Agricultura Familiar (79\%), 812.283 famílias de

\footnotetext{
1 Entre 2003 e 2004 foram homologados pelo Conselho Nacional de Desenvolvimento Rural Sustentável e Solidário (CONDRAF), órgão regulador do programa, 88 territórios rurais. No período de 2005 a 2008 mais 77 territórios foram incorporados ao programa, totalizando 165 territórios rurais. Em 2013 foram homologados outros 74 territórios rurais, e entre 2015 e 2016 mais 4 territórios inseriram-se ao Pronat totalizando 243 territórios rurais.
} 
assentados da Reforma Agrária (84\%), 2.093 comunidades quilombolas (87\%) e 652.582 famílias de pescadores (66\%). Entre 2003 e 2014 o Programa investiu cerca de $\mathrm{R} \$ 3$ bilhões $^{2}$ no financiamento de 7.910 projetos $^{3}$.

Estudos recentes sobre o PRONAT (Valencia et al, 2020; Caniello, 2016; Delgado e Leite, 2015), destacam a gestão social como uma das dimensões mais bem-sucedidas na execução do Programa, mas mencionam também a importância do fortalecimento da governança territorial como ação relevante. De fato, os espaços de participação geram uma base de articulação entre poder público e sociedade civil que antes não existia e, assim, a centralidade outorgada às pessoas, à coordenação, cooperação e corresponsabilidade na gestão da política territorial levou ao estabelecimento de estratégias de monitoramento e avaliação do PRONAT voltadas a avaliar a gestão social.

A SDT começou a desenhar o seu sistema de monitoramento e avaliação em 2007. Na ocasião, o PRONAT era uma novidade e sua abordagem territorial desafiadora exigiu que, nos primeiros anos de execução do programa, fosse priorizada a mobilização de distintos atores sociais para a consolidação dos colegiados, a ampliação de capacidades locais, a identificação de demandas, a formulação e a execução de projetos, sobretudo, de investimento em infraestrutura.

Depois dessa primeira fase de desenvolvimento do programa e na iminência do lançamento do Programa Territórios da Cidadania (PTC), em 2008, política que viria a ser uma ação de escalamento do PRONAT, conforma-se a Coordenação de Gestão Estratégica (CGE) na SDT, tendo como atribuições desenhar e gerir o sistema de monitoramento e avaliação. O sistema foi projetado, implantado, estruturado e posto em prática com a colaboração de diversos atores relevantes entre 2007 e 2016, como os próprios atores territoriais, na figura da Rede Nacional de Colegiados $^{4}$, e as equipes de pesquisadores e pesquisadoras de diversas universidades públicas e institutos federais do país mobilizadas para tal ${ }^{5}$.

Especificamente, a avaliação da gestão social foi desenvolvida em dois ciclos de monitoramento e avaliação, configurando-se como um processo descentralizado que resultou na concepção de um indicador composto por diversos indicadores relevantes teórica e metodologicamente, enfeixados no Índice de Gestão Social (IGS), cuja construção privilegiou a bricolagem (Javeau, 2001), a aprendizagem (Piraux et al, 2010) e a hibridação (Piraux e Bonnal, 2010).

O objetivo deste artigo é mostrar como cada uma dessas dimensões se evidencia no processo de construção do IGS, contornando processos políticos na busca de produzir um indicador útil e pertinente. Com isso, pretendemos contribuir para a reflexão sobre o uso de índices e indicadores na avaliação de mecanismos de governança participativa e apresentar uma proposta metodológica baseada nos

\footnotetext{
2 Valores atualizados pelo IGP-DI (FGV), base: dezembro de 2014. Fontes: CEF (/05/2015); CGMA/SDT/MDA (06/2015).

${ }^{3}$ Fonte: SDT/MDA, 2015.

${ }^{4}$ Instância de governança representativa dos Colegiados Territoriais que atua em nível nacional e se constituiu como importante espaço de gestão e participação social.

${ }^{5}$ Chamadas Públicas MDA/SDT/CNPq No. 05/2009 e CNPq/MDA/SPM-PR Nº 11/2014.
} 
próprios preceitos da chamada "gestão social" para a análise da prática de governança territorial no Brasil ${ }^{6}$.

O artigo parte do marco teórico de construção do IGS e discute a evolução de um termo controverso como é a gestão social e sua relação com a governança territorial. Posteriormente, são descritos os dois ciclos do sistema de monitoramento e avaliação da SDT para, finalmente, detalhar a composição do IGS e suas contribuições para o conjunto de estratégias que visam avaliar processos de governança territorial. Na última parte do artigo arriscamos algumas conclusões e proposições.

\section{Gestão social e governança territorial}

A gestão social e a governança territorial são os dois conceitos fundantes que orientaram o desenho do IGS, os quais passaremos a sumariar nesta seção.

\section{A Gestão Social}

A gestão social é uma noção que surge, inicialmente, de discussões no interior das ciências da Administração e posteriormente consolida-se no campo da gestão pública. O contexto que engloba essa discussão está caraterizado pela busca de uma "cultura política não autoritária na sociedade" (Delgado e Grisa, 2015, p. 52), que, no marco da redemocratização no Brasil, favorecera o protagonismo dos movimentos sociais e outros atores da sociedade civil. Essa busca aprofunda-se nos primeiros anos do século XXI, quando se vincula à descentralização governamental e à promoção de espaços públicos preenchidos por atores externos ao sistema político tradicional (Delgado e Grisa, 2015).

Em meados da década de 1990, aparecem as primeiras referências ao conceito na voz de pesquisadores como Tenório e Cançado (Cançado et al, 2013a; 2013b), que fundamentam os seus estudos em referenciais teóricos, como o conceito habermasiano de "cidadania deliberativa" (Salgado et al, 2019), o qual é proposto para mediar as relações entre Estado, mercado e sociedade civil seguindo princípios como inclusão, pluralismo, igualdade participativa, autonomia e bem comum (Cançado et al, 2013a, p. 112), com o propósito de orientar os processos de discussão e outorgar legitimidade às decisões.

Soma-se a essa abordagem a crítica que estudiosos como Paes de Paula (2005) e Tenório (2005) fazem, a partir do campo da gestão pública, à visão gerencialista das reformas de Estado de segunda geração, pois embora elas propusessem ações de longo prazo para promover mudanças estruturais nas capacidades administrativas e institucionais (Souza e Carvalho, 1999), a evolução em relação ao interesse público e à democracia permaneciam, tão somente, como desafios (Paes de Paula, 2005). Dessa forma, constrói-se um referencial que se sustenta na necessidade de diminuir a brecha entre os aspectos instrumentais da gestão (eficiência dos processos gerenciais) e os aspectos sociopolíticos, para o que se propõe articular as dimensões econômico-financeira, institucional-administrativa

\footnotetext{
6 Neste trabalho não apresentamos os resultados do processo de avaliação, o que faremos brevemente.
} 
e a sociopolítica (Paes de Paula, 2005). Essa última dimensão ganha maior destaque e vem a conformar a vertente societária de uma gestão pública que orienta a conformação de novos arranjos institucionais a partir da esfera pública (Tenório, 2005) para garantir, além dos direitos dos cidadãos, sua participação nos processos de tomada de decisão.

Na tentativa de ligar a gestão social a uma teoria de mudança, Paes de Paula (2005) se baseia na definição de desenvolvimento, construída por Furtado e ainda vigente, na qual a mudança estaria marcada pelo "caminho de acesso a formas sociais mais aptas a estimular a criatividade humana e responder às aspirações da coletividade" (Furtado, 2004, p. 3). De forma complementar, o desenvolvimento associa-se à capacidade cultural do país para formular um projeto nacional e aumentar as capacidades políticas e administrativas para implementá-lo (Paes de Paula, 2005).

A tensão entre gestão e política caracteriza o esforço pela construção teórica da gestão social. Tanto na tomada de decisões quanto nos processos de implementação se faz necessário levar em conta assuntos técnicos (gerenciais), como as habilidades para administrar conflitos e interesses (Paes de Paula, 2005). Sob essa perspectiva, Cançado et al (2013), citando Tenório (2008), retoma a esfera pública como aquela onde há intermediação entre Estado, sociedade e mercado. Nesse espaço, a participação deliberativa concretiza-se na medida do entendimento entre as partes, além da negociação e convencimento.

Em síntese, esses autores entendem gestão social como um "processo gerencial dialógico em que a autoridade decisória é compartilhada entre os participantes da ação" (Cançado et al, 2013, p. 114) e esclarecem que o "substantivo gestão será entendido como o espaço privilegiado de relações sociais no qual todos têm o direito à fala, sem nenhum tipo de coação" (Idem).

Analisar esse referencial no marco de uma política pública como o PRONAT ajuda a entender porque em sua implementação optou-se pela operacionalização da gestão social. Com efeito, a base da construção dos territórios está na força e qualidade das relações sociais que nele se constituem, os caracterizando enquanto tais e se configurando para além de preocupações meramente setoriais. Nesse sentido, a SDT partiu do pressuposto que mediante esse processo de gestão social seria possível articular as redes existentes nos espaços rurais para determinados objetivos, o que redundaria em dinâmicas virtuosas nos territórios rurais.

Assim, a gestão social é um processo participativo de debate, disputas e concertação sobre o planejamento, implementação, avaliação e monitoramento de políticas públicas voltadas para o desenvolvimento rural, processo este que, projetavam os formuladores da estratégia, deslindaria uma dialética ativa, produtiva e progressiva entre identidade, participação social e desenvolvimento rural sustentável (Caniello et al, 2013).

Nesse sentido, para o ente governamental responsável por sua implementação, a gestão social foi considerada como uma forma de gerir assuntos públicos com o objetivo principal de compartilhar o poder de decisão entre o Estado e a sociedade civil (BRASIL, 2010) e, portanto, a efetivação da gestão social dependeria de sistemas descentralizados, com forte participação, fluidez e densidade de informação e articulações em rede (Brasil, 2005). 
$\mathrm{Na}$ busca por cumprir esses princípios, desenha-se o ciclo de gestão social (Figura 1), que se constitui de: (i) ações de planejamento, cujo principal instrumento é o Plano Territorial de Desenvolvimento Rural Sustentável (PTDRS); (ii) a organização, materializada no colegiado territorial; (iii) a coordenação, operada por mediadores; e (iv) o controle social de políticas públicas, realizado através de instrumentos de monitoramento e avaliação das ações territoriais, cada um sendo ligado a quatro princípios: a participação vinculada ao planejamento; a descentralização como evidência da coordenação; a democracia como produto da organização; e a transparência ligada ao controle social. Conforme analisam Oliveira, Valencia e Conterato (2013), a coordenação está vinculada mais estreitamente com o processo societário enquanto os outros correspondem mais a processos de gestão estratégica.

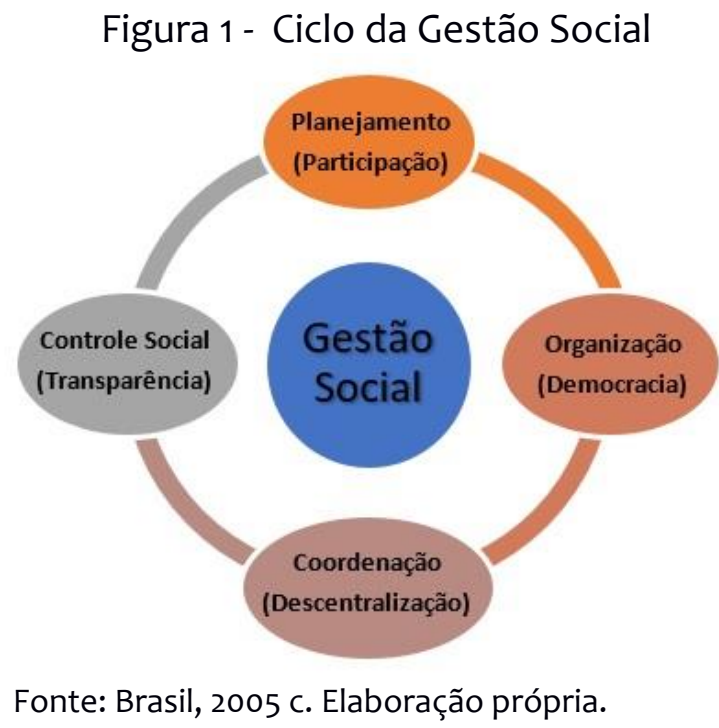

As críticas à noção de gestão social centram-se mais na dificuldade de alcançar os resultados dela esperados e menos no conceito em si. Nesse sentido, observa-se que a hibridação entre o gerencial e o societário confunde a eficiência demandada nos moldes do setor privado com a geração de valor da ação pública mediada pela participação e o respeito aos valores democráticos.

Outros questionamentos referem-se à instrumentalização do conceito a partir do ciclo da gestão social. Por um lado, aponta-se para uma homogeneização que supõe que as soluções dos problemas dos territórios rurais sejam universais, desconhecendo os traços diferenciadores específicos entre esses territórios (Delgado e Leite, 2013). Por outro lado, cai-se no dilema das "sequências invertidas" estudadas por Hirschman (1984), nas quais certos requisitos podem ser "desempossados" (Idem, p.13) e aparecer outros "passos" que gerem os movimentos desejados. Como explicado por Delgado e Leite (2013), os processos de capacidade governativa, como será tratado a seguir, estão além dos processos administrativos gerenciais do Estado. 
Teorias sobre governança territorial

O conceito de governança territorial é polissêmico (Simoulin, 2007), pois traduz usos variados em contextos e realidades diferentes. Nos referimos aqui à governança territorial como um processo de coordenação de atores para atingir objetivos comuns, que privilegiam as relações horizontais e mais flexíveis ao invés de relações hierárquicas de governo (Piraux et al, 2010). A governança territorial questiona a lógica top-down, que considera apenas os níveis locais como receptáculos das decisões governamentais. O conceito, então, é mais amplo que o ligado à "boa governança" definida pelo Banco Mundial numa visão normativa (Torre, 2011). Assim, ele está ligado às redes auto-organizadas e envolvem complexos de organizações, instituições e atores provenientes dos setores público e privado, destacando-se a importância da participação das diferentes partes, levando-se em conta as suas diferentes visões (Rey Valette et al, 2014).

Por consequência, ressalta-se uma definição da governança territorial que destaca a articulação de uma diversidade de "atores sociais, econômicos e institucionais com redes de poder socioterritoriais, de planejamento e gestão de dinâmicas territoriais, que dá prioridade a uma ótica inovadora, partilhada e colaborativa por meio de relações horizontais" (Dallabrida, 2015, p. 325). Mas os stakeholders têm recursos assimétricos e a coordenação deles, reunidos em torno de desafios territorializados, tem que contribuir à elaboração, ocasionalmente conflituosa, de projetos comuns para o desenvolvimento dos territórios (Torre e Traversac, 2011, p. 53).

Para permitir o diálogo e a construção desses projetos entre a sociedade civil e o Estado ao nível dos territórios, arranjos institucionais são necessários. Eles podem ser considerados como a reconfiguração de sistemas de atores engajados na ação pública. Os arranjos se concretizam em dispositivos de governança que organizam a relação entre atores e seus jogos, objetivos, regras e ferramentas (Moisdon, 1997). Assim, a governança territorial deve ser considerada como um processo que vai propiciar que atores, conforme a qualidade dos arranjos construídos, possam debater, escolher e avaliar juntos as decisões no processo de construção do seu devir.

Apesar do conceito ter sido elaborado na Europa, onde as partes interessadas são mais informadas e organizadas nos processos decisórios, ele é cada vez mais usado nos países em desenvolvimento. No entanto, seu uso tem que levar em consideração as grandes assimetrias entre os atores e o nível de capital humano, social e institucional em cada situação dada (Piraux et al, 2010). Como bem lembra Leite (2014), os espaços de participação não são "mágicos", cuja organização, por si só, vá favorecer a articulação entre o Estado e a Sociedade Civil. Para isso, se faz necessário fomentar as capacidades estatais dos atores públicos, como as capacidades da sociedade civil e de diálogo entre os diferentes atores territoriais (Valencia et al, 2019). Segundo Gomide (2016), as capacidades estatais estão associadas à qualidade da burocracia pública e dos canais operacionais que conectam o aparato político administrativo do Estado com a sociedade civil. 
As capacidades exigidas para atingir esse objetivo são técnicoadministrativas e políticas, referindo-se as primeiras às competências na implementação de políticas, coordenando ações para alcançar resultados (Gomide e Pires, 2014). As capacidades políticas se manifestam quando o Estado tem a habilidade de se comunicar e negociar com os atores sociais, estabelecer canais de interlocução, reduzir conflitos e impedir a captura por interesses específicos (Idem). É neste sentido que o conceito de gestão social se junta à visão sobre a governança territorial.

Além da origem geográfica dos termos, pois "gestão social" é um conceito formulado no Brasil e "governança territorial" na Europa, não há diferenças significativas entre essas duas noções. Seja como for, o conceito de gestão social aponta para valores específicos (transparência, bem comum, inclusão) que a governança subentende, mas não destaca. Por outro lado, tratando-se especificamente da gestão social no marco do PRONAT, ele operacionalizou a sua prática num ciclo. Como se verá na seção sobre a construção do IGS, essa tentativa de aproximar esses conceitos vai no sentido da "collaborative governance" conceituada por Ansell e Gash (2007).

\section{Uma longa trajetória no desenho e aplicação do IGS}

O processo de implementação da estratégia de monitoramento e avaliação do PRONAT passou por mudanças na gestão da SDT e pode ser dividida em duas fases caracterizadas por reorientações da política territorial e pela implementação de dois grandes projetos em parceria com o CNPq e universidades públicas: o “Projeto Células", desenvolvido entre 2007 e 2011, e o "Projeto NEDETs", entre 2013 a 2016".

O sistema de acompanhamento, monitoramento e avaliação do PRONAT foi estruturado inicialmente pela sistematização de informações territoriais a partir de bases de dados oficiais como as do IBGE. Esse sistema se mostrou de grande utilidade, sobretudo, nos momentos de tomada de decisão pelos gestores da SDT no sentido de priorizar ações por regiões do país e definir, dentro do grupo dos 165 territórios rurais atendidos pelo programa em 2008, quais iriam a compor o Programa Territórios da Cidadania. Posteriormente, foi implantado o Sistema de Gestão Estratégica (SGE), que visava contribuir para a gestão dos processos da Secretaria, avaliar os resultados do PRONAT, além de apoiar o aprimoramento da gestão social nos territórios rurais (Valencia, 2014).

Para isso, uma equipe de servidores federais e consultores desenharam cinco pesquisas - envolvendo referencias teóricos, metodologia e instrumentos de coleta - estruturadas em cinco indicadores sintéticos, homologados pela secretaria:

\footnotetext{
7 Em maio de 2016, vale sublinhar, o MDA e o Pronat foram extintos pelo governo Temer. No entanto, por tratar-se de recursos descentralizados e contratados mediante a parceria com o CNPq, manteve-se a execução dos projetos, muito embora, com dificuldades operacionais decorrentes das mudanças estruturais.
} 
- Capacidades institucionais $(\mathrm{Cl})$ : permite criar estratos territoriais em relação ao avanço no desenvolvimento institucional, fundamental para o sucesso da gestão social e da execução da política.

- Gestão do colegiado (GC): permite acompanhar a conformação, organização, coordenação, representação e tipo de atividades desenvolvidas pelos Colegiados.

- Avaliação de projetos: permite mensurar a eficiência na gestão e o impacto de projetos financiados pelo PRONAT para entender processos de planejamento, execução e impacto.

- Identidade territorial: para identificar as identidades territoriais, partindo da ideia que a identidade é uma característica do território.

- Índice de condições de vida (ICV): calculado a partir de uma amostra probabilística de famílias nos territórios.

\section{a. O Projeto Células}

Para que o acompanhamento, aliado à informação, estivesse ancorado nos territórios, foi concebida a criação de "Células de Acompanhamento e Informação" (CAls), $r$ operacionalizadas através da parceria entre o colegiado territorial, universidades públicas e a SDT/MDA. Essa parceria surgiu da convergência entre interesses e necessidades dos vários atores envolvidos, mas, sobretudo, devido à necessidade do governo federal de acompanhar e avaliar os resultados dos processos em curso nos territórios, potencializar as relações das universidades com o ambiente social em que estão inseridas e propiciar o aporte crescente de conhecimentos e capacidades, fomentando o incremento do potencial de desenvolvimento e autonomia nos territórios (Brasil, 2008 p. 6).

Essa iniciativa articulou institucional e operacionalmente a SDT, o CNPq e 26 universidades federais e estaduais situadas em 37 territórios rurais, cobrindo 307 municípios localizados em 18 Unidades da Federação ${ }^{8}$. Em agosto de 2010, foi realizado $\mathrm{o} \mathrm{I}^{\circ}$ Encontro das CAls, marco inicial das atividades.

Com o propósito de obter dados comparáveis entre o conjunto de territórios para cada um dos índices aplicados, os instrumentos de pesquisa foram formatados e homologados previamente pela SDT, o que ocasionou uma certa resistência por parte dos colegiados e das equipes de pesquisadores. Por um lado, essas equipes consideravam que o "fechamento" do modelo da pesquisa pela SDT excluía os aportes que pesquisadores poderiam fazer aos desenhos metodológicos e instrumentos de coleta de dados. Por outro lado, alguns colegiados viam as equipes das universidades como agentes externos ao território e temiam que isso pudesse vir a limitar a restituição dos resultados da pesquisa, considerados fundamentais para aprimorar a gestão daqueles fóruns deliberativos.

\footnotetext{
${ }^{8}$ Chamada Pública MDA/SDT/CNPq - Gestão de Territórios Rurais №. 05/2009.
} 
Em abril de 2011, após a conclusão das pesquisas nos 37 territórios, foi realizado o ${ } \mathrm{I}^{\circ}$ Encontro das CAls para divulgar os resultados e discutir ações para um segundo ciclo de pesquisas. Um dos principais encaminhamentos foi a criação de um Grupo de Trabalho composto por coordenadores de CAls de universidades das cinco regiões brasileiras e a equipe da SDT, a fim de diminuir a tensão gerada entre os gestores públicos, as universidades e os colegiados territoriais. Todavia, o maior desafio foi orientar as equipes de pesquisa sobre as análises dos dados obtidos no primeiro ciclo e definir a estrutura de um segundo ciclo de pesquisas, o que se objetivou no aprimoramento dos instrumentos de avaliação da gestão nos colegiados territoriais.

Até esse momento, o SGE disponibilizava o aplicativo "Colegiados em Rede" para coleta de informações dos processos de gestão dessas instâncias. Apesar de ter sido desenhado, testado e implementado com o acompanhamento da Rede de Colegiados Territoriais, a ferramenta não foi apropriada por eles e, assim, a manutenção dos dados foi bastante exíguo. Além do aplicativo, o questionário para avaliar a gestão dos colegiados mostrara-se limitado e não respondia a esse propósito, ficando aquém das informações necessárias para avaliar o ciclo da gestão social e os resultados da governança territorial.

Quanto ao questionário do $\mathrm{ICl}$, os resultados obtidos não permitiram uma boa compreensão do funcionamento dos colegiados devido à falta de clareza conceitual dos indicadores como, por exemplo, o referente à "gestão dos conselhos", que agrupou o funcionamento dos conselhos municipais com o do colegiado territorial. Ademais, foram identificados vários outros problemas: redundância de algumas informações entre indicadores; indicadores informados por um número insuficiente de perguntas; falta de elementos quantitativos (como a existência de um plano, número de reuniões, participantes etc.); qualificação da amostragem de pessoas a serem pesquisadas.

Em vista disso, houve um triplo encaminhamento. O primeiro foi no sentido da construção de um novo $\mathrm{ICl}$, para avaliar as capacidades institucionais de cada município, independentemente de sua relação com o colegiado territorial. $O$ segundo encaminhamento era relativo à elaboração de um novo índice, o IGS objeto deste artigo - composto, concretamente, por uma lista de indicadores que o GT de coordenadores e algumas CAls acharam importante identificar, agrupados em três dimensões: participação, arranjos institucionais e resultados. Essas dimensões, como será detalhado mais adiante, foram denominadas de outra forma, mas seus referenciais se mantiveram ao longo da trajetória de construção do índice. $O$ terceiro encaminhamento foi a respeito da elaboração de um índice para a avaliação de projetos de investimento do PRONAT nos territórios, uma tarefa nada simples porque envolvia vários problemas ligados à natureza do objeto a ser avaliado, uma vez que os projetos de infraestrutura possuíam diferentes conformações nos territórios e estados em que eram desenvolvidos.

Depois de um processo de consulta às Células e debates internos, o GT ajustou e finalizou os questionários do IGS, cujo pré-teste foi aplicado em nove territórios cujas CAls eram coordenadas pelos componentes do grupo. Durante a fase de testes era prevista a realização de ajustes na fórmula dos índices, tendo como base a ponderação entre os indicadores que compõem os índices. Entretanto, isso não foi possível porque o SGE, anteriormente hospedado na própria SDT, foi 
deslocado para o centro de processamento de dados do MDA, em decorrência de recomendação de órgão de controle do governo federal. Essa mudança, embora estratégica para a unificação do gerenciamento de informações pelo ministério, foi realizada sem mudanças estruturais e organizacionais, o que dificultou a reestruturação do fluxo de informações por parte da SDT. Isso levou a uma situação de incerteza no que tangia às responsabilidades a serem exercidas no fornecimento e gerenciamento de dados.

De qualquer forma, o instrumento de coleta de dados foi aplicado a 783 representantes ativos nos colegiados em 33 territórios rurais, entre novembro de 2012 e março de $2013^{9}$ e os resultados da pesquisa foram consolidados em fevereiro de 2014. A interrupção temporária do PTC por mais de um ano e meio ${ }^{10}$, exatamente no momento de coleta de dados do segundo ciclo de avaliação, dificultou fortemente o exercício, exatamente em decorrência da dificuldade de se mobilizar os participantes dos colegiados.

Havia sido planejada uma interpretação coletiva dos dados obtidos que seria realizada em um Encontro final do "Projeto Células", mas após mudanças políticas internas no MDA e as limitações operacionais impostas legalmente devido à proximidade das eleições presidenciais, isso não ocorreu. Infelizmente, pois esse debate teria possibilitado avaliar mais claramente as razões das diferenças entre territórios, além de colocar em perspectiva as informações básicas disponíveis para cada Célula e dar sentido um sentido orgânico a todos os resultados ${ }^{11}$.

No que diz respeito à avaliação da eficiência do IGS foi necessário considerar o conjunto dos seus indicadores e, nesse caso, um dos aspectos relevantes foi justamente a ocorrência de ponto médio para parte significativa dos indicadores que compunham o índice, denotando a necessidade de adequação metodológica (Piraux e Caniello, 2019). Com o término da vigência contratual isso somente foi possível com a implantação dos Núcleos de Extensão em Desenvolvimento Territorial (NEDETs), sobre os quais abordaremos em seguida.

\section{b. O Projeto NEDETS}

Os Núcleos de Extensão em Desenvolvimento Territorial (NEDETs) surgiram da experiência e do processo de aprendizagem decorrentes do Projeto Células e, para viabilizá-los, a SDT firmou uma nova cooperação com o CNPq. Essa parceria resultou num edital que disponibilizou a universidades e institutos federais recursos financeiros estimados em mais de 86 milhões de reais, descentralizados do MDA para o CNPq, o maior volume de recursos destinado à extensão universitária em uma chamada pública na história daquela agência de fomento ${ }^{12}$.

\footnotetext{
9 A amostra tomou por base o mínimo de dois representantes por município que compunha o território, a saber, um representante do poder público e um da sociedade civil, respeitando a paridade dentro dos colegiados. Assim, a amostra foi de 1.214 respondentes, projetada para 783 questionários aplicados, o que representa $64,50 \%$ de abrangência desse instrumento.

${ }^{10}$ Esta paralisação ocorreu em 2011, início do $1^{\circ}$ mandato de Dilma Rousseff na presidência da República.

${ }^{11}$ Seja como for, posteriormente os dados foram analisados por dois componentes do GT de coordenadores (Cf. Piraux e Caniello, 2019).

${ }^{12}$ Chamada Pública CNPq/MDA/SPM-PR Nº 11/2014.
} 
Diferentemente das Células, cujas ações eram centradas fortemente na pesquisa, os NEDETS abarcavam também o apoio técnico aos colegiados, antes viabilizado pela "terceirização" dessa atividade através de repasse de recursos públicos a Organizações Não Governamentais (ONGs) que ofereciam assessoramento aos colegiados territoriais (Delgado e Rocha, 2017). Os inúmeros problemas decorrentes da descontinuidade do assessoramento territorial combinados com a suspensão dos contratos de repasse por decreto presidencial, exigiu da Secretaria inovações em sua estrutura de governança territorial (Delgado e Rocha, 2017, p. 147; Caniello e Teixeira, 2017, p. 22).

A busca por um desenho institucional mais estável de prestação de serviços aos Colegiados resultou na constituição de uma rede pública de assessoramento aos territórios rurais mediante implantação, em duas etapas, dos NEDETs, que tinham por objetivos: (i) produção de dados, informações e conhecimentos com vistas à elaboração de pesquisas; (ii) difusão de métodos e tecnologias sociais voltadas para a gestão social; (iii) monitoramento, avaliação e assessoria técnica aos colegiados territoriais; e (iv) realização de reuniões territoriais.

Devido à complexidade de operacionalização técnica da parceria, a SDT e o CNPq decidiram, antes de lançar o edital, implementar um projeto piloto na modalidade "encomenda" para conformar esses primeiros núcleos, levando-se em conta a representatividade regional, experiências anteriores das CAl's, como o saber e a prática de outros grupos de consultores e pesquisadores conhecedores da temática territorial.

Inicialmente, na primeira etapa, a SDT propôs 16 projetos, em dezembro de 201314 projetos foram apresentados junto ao CNPq que, após análise de todos os parâmetros internos, aprovou 12 envolvendo 10 Instituições de Ensino para atuar em 56 territórios rurais localizados em 8 Unidades da Federação, sendo: 32 territórios da cidadania, 10 novos territórios e 14 territórios rurais. No que se refere ao formato, fortaleceu-se a ação de extensão com previsão de contratação de assessores territoriais em duas modalidades: gestão social e inclusão produtiva.

O início das atividades dos NEDETs guarda particularidades referentes à experiência e capacidade organizativa dos coordenadores dos projetos pois, para alguns docentes, tratava-se da primeira parceria institucional tanto com o CNPq, quanto com instâncias do poder público federal. Além disso, alguns dos projetos englobavam territórios novos, recém homologados, com inúmeras dificuldades de mobilização do tecido social e de vivência da política territorial. Esses fatores resultaram num processo mais lento de implementação das ações e até mesmo de contratação dos assessores para formação das equipes, o que gerou um descompasso entre aspectos legais e formais da constituição dos Núcleos e a agenda de ações propostas pela SDT.

Concomitantemente, avaliados os aprendizados da experiência piloto e, na medida do possível, ajustados, em maio de 2014 foi lançada a Chamada Pública para a segunda etapa dos NEDETs no intuito de abranger os 239 territórios rurais existentes naquele período. Três importantes inovações foram propostas: (i) os projetos poderiam ser individuais para implantação de um Núcleo ou multiterritoriais para no máximo 5 Núcleos por coordenador de projeto; (ii) expansão das parcerias com universidades federais e estaduais e, também, com Institutos Federais; e (iii) para os territórios da cidadania, estava prevista a 
contratação de um assessoramento de gênero, isto decorreu da parceria da SDT com a Diretoria de Políticas para Mulheres Rurais (DPMR) e a Secretaria de Políticas para Mulheres da Presidência da República (SPM) com aporte de recursos para ações nos territórios integrantes do PTC.

Nesta etapa foram então contratados 90 projetos para implantação de 137 NEDETs em 65 territórios da cidadania, 51 novos territórios e 21 territórios rurais. Os esforços das duas etapas resultaram na implantação de 188 Núcleos vinculados à 54 Universidades ou Institutos Federais responsáveis por assessorar 188 Colegiados Territoriais.

Em julho de 2015 ocorreu em Brasília o I Encontro Nacional dos NEDETs, oportunidade em que professores coordenadores dos 186 núcleos participaram durante 3 dias de atividades de planejamento das ações envolvendo um conjunto de políticas públicas como PROINF, ATER, PRONAF, etc. Durante essas atividades, os resultados dos indicadores produzidos pelas Células foram apresentados, dentre eles o IGS. Na plenária constituiu-se um novo Grupo de Trabalho com participação de dois representantes da SDT e oito docentes das universidades parceiras, com atribuição de realizar o ajuste da metodologia e do instrumento de coleta de dados do IGS A partir daí, o GT passou a reunir-se periodicamente, sobretudo para afinar as questões relativas às diferentes dimensões dos indicadores do índice, sobre a amostra da pesquisa e formas de aplicar os questionários.

Em novembro de 2015, em Salvador/BA, realizou-se o II Encontro Nacional dos NEDETs para avaliação das atividades desenvolvidas e planejamento para o exercício 2016. Nesta oportunidade, o GT IGS apresentou o trabalho desenvolvido e foi pactuado entre SDT e equipes dos NEDETs a aplicação dos questionários junto aos integrantes dos Colegiados Territoriais a partir de março de 2016. Antes disso, foi realizado um pré-teste em territórios selecionados que resultaram em adequações metodológicas ocasionando atraso no processo. Portanto, a aplicação do novo instrumento nos 186 territórios rurais apoiados pelos NEDETs, foi iniciada partir de maio 2016, resultando em 3910 questionários respondidos em 140 territórios.

Apesar do ambiente de tensão e de insegurança institucional que se configurou pelo impeachment da presidenta Dilma Rousseff, os gestores da SDT mantiveram suas ações planejadas junto aos Núcleos. Assim, entre 14 de abril e 06 de maio, cinco Encontros Regionais dos NEDETs foram realizados e uma das principais ações naquele momento foi a capacitação das equipes para aplicação do questionário IGS junto aos Colegiados Territoriais, assim que a apresentação de uma estratégia que pudesse garantir a divulgação dos resultados dos dados produzidos a fim de contribuir para pesquisas e análises futuras.

A estratégia dos NEDETs configurou-se como uma evidência da intencionalidade de um "novo formato na estrutura da governança da política territorial que conferisse maior capilaridade para a gestão pública mediante a consolidação de uma rede capaz de promover maior dinamização e sustentabilidade ao território" (Delgado e Rocha, 2017, p. 148 e 152). Cada um dos formatos aqui apresentados - Células e NEDETs - obedeceram a necessidades específicas da gestão do PRONAT, mas sua trajetória mostra um processo de continuidades mediadas por um importante conjunto de aprendizagens. Entre eles, a aproximação ao $\mathrm{CNPq}$, universidades e institutos, para gerir ações de monitoramento, avaliação e 
extensão e, aliado a isso, a importante troca de conhecimentos entre todos os envolvidos. Também houve rupturas que levaram a interrupções, paralisações e cancelamentos no processo de monitoramento e avaliação no âmbito das ações de extensão. Essas rupturas se deveram, principalmente, a processos políticos comuns na gestão pública como a mudança de secretários da SDT, ou mais drásticos como o próprio impeachment em 2016.

\section{I Índice de Gestão Social (IGS)}

Como mencionado anteriormente, o Índice de Gestão Social (IGS) remete à análise do funcionamento dos Colegiados Territoriais e seu desempenho, permitindo aferir a situação das articulações e recursos que possibilitam a gestão social dos territórios, a partir de questões e entrevistas realizadas com os membros dos colegiados. Esse trabalho de avaliação dos arranjos de governança descritos aqui é específico, pois trata apenas da eficácia e utilidade das ações desenvolvidas pelos Colegiados e não cobriu questões relacionadas à eficiência (que mede a relação custo/benefício) e à coerência entre objetivos e realizações.

O trabalho de Ansell e Gash (2007) sobre a governança colaborativa, que julgamos próximos das teorias da gestão social, inspiraram o quadro de análise descrito a seguir (figura 2).

Figura 2. Quadro Analítico do IGS

\begin{tabular}{|c|c|c|c|}
\hline $\begin{array}{l}\text { GESTAO } \\
\text { SOCIAL }\end{array}$ & \multicolumn{3}{|c|}{$\begin{array}{c}\text { INSTITUCIONAL DESIGN } \\
\text { (Quadro normativo, tipo de organização) }\end{array}$} \\
\hline \multirow{3}{*}{$\begin{array}{l}\text { CONTEXTO } \\
\text { - Assimetrias } \\
\text { - Nível de } \\
\text { capital social } \\
\text { - Capacidades } \\
\text { institucionais }\end{array}$} & Participação & $\begin{array}{c}\text { Processos } \\
\text { colaborativos }\end{array}$ & Resultados \\
\hline & $\begin{array}{l}\text { Mobilização } \\
\text { Representação }\end{array}$ & $\begin{array}{c}\text { Gestão } \\
\text { Informação e ciclo de GS }\end{array}$ & $\begin{array}{l}\text { Outputs } \\
\text { Plano e projetos }\end{array}$ \\
\hline & $\begin{array}{l}\text { Consenso } \\
\text { Decisão }\end{array}$ & $\begin{array}{c}\begin{array}{c}\text { Planejamento e controle } \\
\text { social }\end{array} \\
\text { Arranjos institucionais }\end{array}$ & $\begin{array}{c}\text { Capital humano, sociale } \\
\text { territorial } \\
\text { Outcomes }\end{array}$ \\
\hline
\end{tabular}

Fonte: Elaboração própria a partir do Ansell e Gash, 2007.

A gestão social, como foi dito, fornece um pano de fundo orientando o funcionamento do dispositivo de governança e a condução da política pública. Assim, o IGS informa as principais características da gestão social entendida como um ciclo contínuo e retroalimentado entre processos de planejamento, organização, coordenação e controle social. 
O contexto social e institucional (figura 2) condiciona esse funcionamento. No caso do Brasil, é um contexto com fortes assimetrias entre atores, desigualdades sociais, capacidades institucionais fracas, ineficiência na integração das políticas públicas e contingências políticas, o que veio a impactar os objetivos específicos do PRONAT.

$O$ design institucional (figura 2 ) refere-se às normas que condicionam a participação e a colaboração entre os atores implicados, regras que são importantes para a construção da legitimidade processual no processo colaborativo (Ansell e Gash, 2007). No caso aqui abordado, o PRONAT definiu os objetivos (erradicação da pobreza e das desigualdades, inclusão da agricultura familiar) e o quadro normativo caracterizando os outputs (os planos territoriais e PROINF) e o tipo de participação no colegiado.

A figura 1 apresenta também as três dimensões da gestão social que privilegiam a participação, os processos colaborativos e os resultados (entre outros o controle social). A ideia é que a qualidade dos processos colaborativos construídos, que constituem a base da gestão social, permite uma real participação dos atores nos colegiados, que impactarão no final a qualidade dos resultados. 0 tipo de processos colaborativos implementados pode conduzir a qualidades de engajamento muito diferentes. Assim, o IGS é composto de 3 dimensões e 9 indicadores e perguntas especificas como apresentado na tabela 1.

As três dimensões são as seguintes:

1. A dimensão da participação é caraterística das teorias da gestão social e da governança. Ela é fundada numa boa representação dos atores locais e estabelece uma diferença entre a mobilização (que corresponde ao fato dos representantes estarem presentes nas reuniões do colegiado e que constitui um indicador) e a decisão (outro indicador), que supõe o entendimento dos assuntos e uma participação ativa e igualitária ao debate através da busca de consenso e não da decisão por maioria. Uma mobilização boa não significa automaticamente uma decisão justa e democrática, que depende do equilibro entre as relações de poder no colegiado. A qualificação do tipo de decisão (por consenso e votação) foi também caracterizada.

2. A segunda dimensão cobre os processos colaborativos necessários para a gestão social e ao bom funcionamento da governança. Se trata de institucionalizar este processo através de mecanismos gerenciais apropriados (Chia et al, 2008). É a dimensão mais clássica da governança, mas que toma um eco especifico à luz da gestão social: os mecanismos de gestão devendo permitir o estabelecimento de arranjos institucionais adequados e transparentes, com regras co-construídas e capacidade de respeita-las, no sentido dos bens comuns (Orstrom, 1999). Metodologias participativas e ferramentas específicas permitindo a apropriação dos processos e a avaliação devem ser pensados para permitir uma aprendizagem organizacional, fundamentais para promover mudanças. 
Esta dimensão avalia a capacidade de conduzir um processo colaborativo através de mecanismos gerenciais adequados (caracterizado pelo indicador 2.1), condicionando a construção de arranjos institucionais eficazes (indicador 2.2). 0 primeiro indicador apoia-se sobre algumas variáveis: capacidade de definição de objetivos e de regras (de funcionamento, tarefas, de escolha e tipo de representação das entidades de base, de definição da pauta das reuniões), caracterização do tipo de animação e, condução do planejamento e da avaliação, repasse de informações, grau de informação e de debate, fontes de recursos financeiros do colegiado (no sentido de diversificar essas fontes e não ficar na dependência da SDT). O segundo indicador avalia o nível de satisfação que os participantes têm dos debates, da liderança e do funcionamento do colegiado.

3. A terceira dimensão corresponde aos resultados da gestão social em termos de outputs (produtos ou plano territorial e implementação de projetos) e outcomes (impactos da gestão social em termos de capital humano, social e institucionais). Os outcomes são particularmente importantes para a gestão social no sentido da criação de bens comuns, confiança, laços entre os atores, identidade territorial. Os impactos da gestão social, os outcomes, constituem cinco indicadores: legitimidade, aprendizagem, territorialização de políticas públicas, compartilhamento de poder e capital social. A questão da descentralização do poder é analisada nas dimensões 2 e 3 (a partir das relações com o CMDRS, do nível de debate sobre as políticas e da territorialização das políticas públicas federais, estaduais e municipais).

Sobre os outputs, como discutido anteriormente, foi prevista a construção de um indicador especifico para avaliar a definição e implementação de projetos. Cada território tinha o seu próprio plano, cujo nível de apropriação e como elemento orientador dos projetos foram avaliados na dimensão 2. 
Avaliar a gestão social na governança territorial: bricolagem, aprendizagem e hibridação na construção do Índice de Gestão Social (IGS)

Tabela 1 - Variáveis constituindo as 3 dimensões do IGS

\begin{tabular}{|c|c|c|}
\hline Dimensão & Indicadores & Questões* \\
\hline \multirow[b]{2}{*}{ 1. Participação } & 1.1. Mobilização & $\begin{array}{l}\text { Avaliação do processo de mobilização } \\
\text { Falta de organizações importantes, quais? }\end{array}$ \\
\hline & 1.2. Decisão & $\begin{array}{l}\text { Nível de participação nas plenárias (e quem) } \\
\text { Influência dos grupos sociais na tomada de decisão } \\
\text { Nível de participação e papel da Plenária nas diferentes etapas } \\
\text { dos projetos PROINF } \\
\text { Tomada de decisão por consenso ou votação } \\
\text { Existência de grupos dominantes }\end{array}$ \\
\hline \multirow[t]{2}{*}{$\begin{array}{l}\text { 2. Processos } \\
\text { colaborativos }\end{array}$} & $\begin{array}{l}\text { 2.1. Processos } \\
\text { gerenciais }\end{array}$ & $\begin{array}{l}\text { Capacidade de gestão (regras de funcionamento do Codeter e } \\
\text { tarefas, animação, objetivos, ciclo de gestão, avaliação, } \\
\text { transparência...) } \\
\text { Regras sobre a representação das entidades de base } \\
\text { Regras sobre a escolha das entidades da plenária } \\
\text { Regras sobre a construção da pauta, da definição da agenda e } \\
\text { planejamento do colegiado } \\
\text { Papel dos NEDETs e do leadership } \\
\text { Organização das decisões para os PROINF } \\
\text { Grau de debate das políticas públicas (e quais) } \\
\text { Papel do PDTRS na orientação das decisões } \\
\text { Repasse de informações nas entidades de base } \\
\text { Fontes de recursos do colegiado }\end{array}$ \\
\hline & $\begin{array}{l}\text { 2.2 Qualidade dos } \\
\text { arranjos } \\
\text { institucionais }\end{array}$ & $\begin{array}{l}\text { Avaliação do nível de funcionamento do colegiado } \\
\text { Elementos que prejudicam o funcionamento } \\
\text { Qualidade do funcionamento dos NEDETs e das ONGs } \\
\text { contratada pela SDT } \\
\text { Nível de informação sobre temas específicos } \\
\text { Qualidade de trocas de informação entre as instâncias do } \\
\text { colegiado } \\
\text { Qualidade do debate com os CMDRS }\end{array}$ \\
\hline \multirow{5}{*}{ 3. Impactos } & 3.1. Legitimidade & $\begin{array}{l}\text { Reconhecimento da legitimidade do colegiado (pelos } \\
\text { participantes e para pessoas de fora) } \\
\text { Benefícios adquiridos para as entidades de bases }\end{array}$ \\
\hline & $\begin{array}{l}\text { 3.2. Exercício do } \\
\text { poder }\end{array}$ & $\begin{array}{l}\text { Mudança do exercício do poder no território } \\
\text { Renovação das lideranças } \\
\text { Hegemonia de grupo(s) no Codeter }\end{array}$ \\
\hline & 3.3. Aprendizagem & $\begin{array}{l}\text { Nível de aprendizagem (capacidades de: diálogo, visão, } \\
\text { resolução de problemas, negociação, avaliação, trocas, } \\
\text { planejamento, expressão em público, relação interpessoal e } \\
\text { gestão dos conflitos, respeito das regras, entendimento das } \\
\text { dinâmicas territoriais) }\end{array}$ \\
\hline & $\begin{array}{l}3 \cdot 4 \text {. } \\
\text { Territorialização } \\
\text { das políticas } \\
\text { públicas }\end{array}$ & $\begin{array}{l}\text { Capacidades de adaptação das PP federais (e quais), estaduais } \\
\text { e municipais }\end{array}$ \\
\hline & $\begin{array}{l}\text { 3.5. Melhoramento } \\
\text { dos laços sociais }\end{array}$ & $\begin{array}{l}\text { Melhoria do diálogo, da confiança, das redes locais, da } \\
\text { colaboração } \\
\text { Sentimento de pertencimento ao território }\end{array}$ \\
\hline
\end{tabular}

*As variáveis sublinhadas tiveram um peso diferenciado na fórmula devido sua importância. 
O questionário conta com 55 perguntas sendo14 perguntas orientadas sobre a identificação dos entrevistadores, 7 na primeira dimensão, 22 para a segunda, 12 sobre a terceira. No final de cada dimensão existe, também, uma pergunta transversal para avaliar como as variáveis evoluíram no decorrer da trajetória do colegiado. Isso permitiu obter uma visão dinâmica dos processos. Essa variável também teve um peso maior no cálculo do índice. Uma formula foi estabelecida a partir da media dentro de cada dimensão para obter 3 indicadores e depois o índice para obter um valor de 0 a 1. É importante ressaltar que o IGS é calculado a partir de uma pesquisa de opinião e não de uma quantificação dos impactos ligados aos recursos realmente implementos. Como já destacamos, não é avaliada a eficiência da política em si, mas bem a sua eficácia.

\section{Considerações Finais}

O desafio e o futuro da política de desenvolvimento territorial exigiam um significativo avanço na integração das políticas para o rural brasileiro e uma consequente ampliação do universo de ações governamentais. Isso demanda, por um lado, o fortalecimento da articulação institucional entre os órgãos federais e os entes federados, e por outro, a consolidação da participação e gestão social nos territórios. Os desafios relacionavam-se também ao apoio sistemático e contínuo às instâncias colegiadas, a produção de dados e informações para fins de monitoramento e avaliação, o exercício de outro desenho de governança capaz de conferir capilaridade de atuação, bem como, o repasse de recursos públicos que garantisse a continuidade e qualidade das ações.

O IGS oferece um quadro analítico pertinente dos processos de gestão social e da governança territorial, em que se destaca a pertinência de sistemas de indicadores para cobrir as diferentes dimensões desses conceitos: a participação, os processos colaborativos e os resultados. Neste sentido, foi necessário trabalhar os impactos (outcomes) e não só os produtos (outputs) e, especificamente, os valores criados, como a melhoria dos laços sociais e da identidade territorial, a qualidade do diálogo, a legitimidade, que são variáveis típicas da gestão social, fora da lógica puramente gerencial. Talvez, a criação de bens comuns teria sido uma variável interessante a integrar, mas essas dimensões intangíveis não são tão fáceis de apreender.

O IGS foi o resultado de um processo longo de construção, implementação e adaptação continuada e, finalmente, queremos destacar três dimensões que foram ativadas nesse processo: a bricolagem, a aprendizagem e a hibridação.

A bricolagem é um conjunto de arranjos entre indivíduos (com vontades e interesses diferentes) e dispositivos técnicos e institucionais que, no curso das interações, não param de fazer, desfazer e refazer a avaliação (Javeau, 2001). A evolução desses arranjos é necessária, tendo em vista a inconsistência dos processos políticos, administrativos e sociais que prevaleceram. A bricolagem é essencial para ajustar gradualmente os indicadores em relação aos resultados obtidos e ao contexto institucional e administrativo evolutivo que prevaleceu durante a avaliação. Implicações metodológicas importantes decorrem disso: usar um corpus metodológico adaptado que evite se prender rapidamente a escolhas irremediáveis e a necessidade de planejar momentos para avaliar a bricolagem "se 
fazendo". Foi o caso na construção do IGS. É necessário um processo permanente de observação, avaliação e ajuste das estratégias de intervenção.

A aprendizagem, quanto a ele, impacta o nível de apropriação dos indicadores. Essa apropriação cobre três desafios: produzir indicadores úteis, usáveis e usados: úteis no sentido de refletir a complexidade dos processos de gestão social e atender aos requisitos dos patrocinadores da avaliação; uma real análise da demanda e sua tradução em indicadores e índices é um trabalho indispensável. Indicadores utilizáveis no sentido de estarem compreensíveis pelos usuários; um indicador é mais do que uma estatística, ele tem um valor comunicativo (Perret, 2003) e um poder de representação da realidade para atrair a atenção dos usuários. Isso justifica também o interesse de índices sintéticos que muitas vezes são impostos por razões pragmáticas, dado seu impacto comunicativo. Eles são simples sem serem simplistas. No entanto, os indicadores também devem estar prontamente disponíveis, como foi o caso do SGE no Brasil. Enfim, para que os indicadores sejam realmente usados, é necessário o fortalecimento das capacidades locais para permitir a apropriação das informações e lembrar sempre as condições em que foram obtidas e dar-lhes significado em um contexto local. Esse trabalho de construção de sentido é fundamental (Muller, 2000) em qualquer processo de avaliação. Os processos de acompanhamento são então cruciais e a experiência das células e dos NEDETs foi uma inovação institucional excepcional neste sentido. A participação dos atores na própria avaliação garante uma maior relevância dos indicadores e melhora sua apropriação.

Apesar disso, podemos destacar a fraqueza do uso do IGS na SDT e ao nível dos territórios, devido a mudanças políticas e a todos os constrangimentos que isso implicou ao funcionamento dos NEDETs. Diferentes estudos concluem que houve um significativo avanço no fortalecimento da uma base social que se organizou nos territórios rurais (Delgado e Leite, 2013; Favareto, 2015; Valencia et al, 2018), mas apesar da ampla capilaridade do programa, apoiando territórios nas diferentes regiões do Brasil, o volume de recursos investidos e seu escalamento como o Programa Territórios da Cidadania, sua extinção não permitiu aproveitar as aprendizagens geradas a partir do sistema de monitoramento e avaliação. A transição de paradigmas precisa de mais tempo e acontecer num contexto favorável à mudança.

Enfim, a hibridação se refere ao cruzamento entre saberes acadêmicos e locais (baseados nas experiências dos professores e técnicos implicados nas ações dos colegiados); entre extensão e avaliação, permitindo o fortalecimento do acompanhamento nos territórios; e combinação de processos interativos entre abordagem normativa e processual entre cruciais para promover uma avaliação ascendente enquadrada com normas nacionais. Favorecer apenas processos de avaliação de baixo para cima poderia dificultar a comparação dos resultados. Nesse sentido, o contexto político constrangeu ainda mais uma vez, fortemente o seu exercício, com eventos como a paralisia do programa PRONAT, entre outros. A instabilidade de procedimentos e contextos políticos também se referem diretamente à inserção institucional do PRONAT dentro do corpo normativo do Estado, que foi periférico (Piraux e Bonnal, 2010). Portanto, um trabalho essencial de conscientização deve promover uma cultura de avaliação que ainda hoje é fraca no Brasil, tanto ao nível local quanto ao nacional. 


\section{REFERÊNCIAS}

ANSELL, C, GASH, A, Collaborative Governance in Theory and Practice. Journal of Public Administration Research and Theory. 18:543-571, 2007.

BOBBIO, N. O futuro da democracia: uma defesa das regras do jogo. $7^{\mathrm{a}}$ ed. Rio de Janeiro: Paz e Terra, 2000.

BRASIL. Ministério de Desenvolvimento Agrário. Referências para uma estratégia de desenvolvimento rural sustentável. Documentos Institucionais, Brasil, n. 1, março 2005a.

BRASIL. Ministério de Desenvolvimento Agrário. Marco referência para apoio ao desenvolvimento de territórios rurais. Documentos Institucionais, n.2, Brasília, jun. 2005b.

BRASIL. Ministério de Desenvolvimento Agrário. Referências para a gestão social de territórios rurais. Documentos Institucionais, n. 3, Brasília, nov. 2005C. BRASIL. Orientação para constituição e funcionamento dos colegiados territoriais. Brasília: MDA, 2009.

CANÇADO, A; PEREIRA, J.; TENÓRIO, F. Gestão Social: epistemologia de um paradigma. Curitiba: CRV Editora, $2013 a$.

CANÇADO, A; SAUSEN, J.; VILLELA, L. Gestão Social versus Gestão Estratégica. In: TENÓRIO, F. (Org). Gestão Social e Gestão estratégica, experiências em desenvolvimento territorial. Rio de Janeiro: Editora FGV, 2013b, p.15-86.

CANIELLO, M. Identidade e Qualidade de Vida nos Territórios da Cidadania na 'Década Inclusiva' Brasileira. Sociologias, Ano 18, n 43, Porto Alegre, p. 300-334, 2016.

CANIELLO, M.; TEIXEIRA, O. A. Os Núcleos de Extensão Universitária em Desenvolvimento Territorial e a governança participativa nos Territórios Rurais brasileiros: origem, processo, dissolução e perspectivas. In: FONTELLES, J.O. (org.), Território e territorialidades. Sobral: Edições UVA e Editora Sertão Cult, 2017, p 3451.

CANIELLO M, PIRAUX M, BASTOS V. Capital social e desempenho institucional no colegiado territorial da Borborema, Paraíba. Raízes 32 (2), p 11-31, 2012.

CHIA E, TORRE, A, REY-VALETTE H. Vers une technologie de la gouvernance territoriale, Palidoyer pour um programme de recherche sur la instruments et dispositifs de gouvernance des territoires. Norois, 209, p 167-177, 2008.

DALLABRIDA V R. Governança territorial: do debate teórico à avaliação da sua pratica. Analise social, 215, L (2 ), p 304-328, 2015. 
DELGADO, N.; GRISA, C. Governança Territorial, Dinâmica Institucional e Protagonismo Social Territorial: Revisitando um Percurso Metodológico seguido pelo Oppa/CPDA no marco dos Estudos Territoriais, ReGIS, v. 1, n. 1, p. 48-66, 2015.

DELGADO N., LEITE S. O PRONAT e o PTC: possibilidades, limites e desafios das políticas territoriais para o desenvolvimento rural in GRISA C., SCHNEIDER S. (coord.), Políticas públicas de desenvolvimento rural no Brasil, Porto Alegre, Editora UFRGS, 2015, p. 239-259.

DELGADO, N G.; ROCHA, B N. Governança Territorial e Gestão Social: avanços e desafios da política territorial de desenvolvimento rural no Brasil In: Questões Agrárias, Agrícolas e Rurais: conjunturas e Políticas Públicas.1 ed., Rio de Janeiro: Epapers, v.1, p. 138-154, 2017.

FAVARETO, A. Uma década de experiências e o futuro das políticas de desenvolvimento territorial rural no Brasil. In: GRISA, C. e SCHNEIDER, S (Org.). Políticas Públicas de Desenvolvimento Rural no Brasil. Porto Alegre: Editora da UFRGS, 2015, p. 261-278.

GOMIDE, A.; PIRES, R. Capacidades estatais e democracia - a abordagem dos arranjos institucionais de políticas públicas. In: GOMIDE, A e PIRES, R (Org.). Capacidades estatais e democracia - arranjos institucionais de políticas públicas. Brasília: IPEA, 2014.

GRISA, C.; SCHNEIDER, S. Três gerações de políticas públicas para a agricultura familiar e formas de interação entre sociedade e estado no Brasil. In: GRISA, C.; SCHNEIDER, S (Org.). Políticas Públicas de Desenvolvimento Rural no Brasil. Porto Alegre: Editora da UFRGS, 2015, p.19-50.

HIRSCHMAN, A. El avance en colectividad. Experimentos populares en la América Latina. México: Fondo de Cultura Económica, 120 p., $1^{a}$ Edición en español, 1986.

JAVEAU, C. Le bricolagem social. Um traité de sociologie. PUF, Paris, 2001.

LEITE, S.P. Governança das políticas públicas para o desenvolvimento territorial rural no Brasil. In: Moreira, R.J. e Bruno, R. (Eds.). Dimensões rurais de políticas brasileiras. Mauad X. Rio de Janeiro. pp. 105-136, 2014.

MANNHEIM, K. Sociologia sistemática: uma introdução ao estudo de sociologia. $2^{\mathrm{a}}$ ed. São Paulo: Pioneira, 1971.

MOISDON, J C. Du mode d'existence des outils de gestion. Seli Arsalan, 1997.

MULLER P. L'analyse cognitive des politiques publiques: vers une sociologie politique de l'action publique. Revue française de science politique, 50, 2, 2000. 
PAES DE PAULA, A.P Por uma nova gestão pública. RJ: Editora FGV, 2005.

PIRAUX, M, BONNAL, P. Ações públicas territoriais e inovações sociais e institucionais. Estudos Sociedade e Agricultura, 19 (1) : p. 62-87. 2011.

PIRAUX, M, AZEVEDO S G, TONNEAU, JP. Os mediadores, os políticos e a sociedade civil. A realidade e os limites da governança territorial. Raizes, 28 e V. 29, n. 1, p. 97108, 2010.

PIRAUX, M., CANIELLO, M. Reflexões retrospectivas e prospectivas sobre a governança territorial para o desenvolvimento rural no Brasil. Raízes: 39(2), p. 359379, 2019.

OLIVEIRA, C. D. e VALENCIA, M. Percepção de Atores Sociais Sobre Gestão Estratégica e Gestão Social no âmbito da Política de Desenvolvimento Territorial, ENAPEGS, 2011.

OLIVEIRA, C.D.; VALENCIA, M; CONTERATO, M. Percepção de atores sociais sobre gestão estratégica e gestão social no âmbito da política de desenvolvimento territorial no brasil. DRd- Desenvolvimento Regional em Debate, ano 3, n. 2, p. 154$175,2013$.

OSTROM E. Design principles and threats to sustainable organizations that manage commons. Center for the Study of Institutions, Population, and Environmental Change. Workshop in Political Theory and Policy Analysis, Indiana University, 1999.

PAULA, A. P. de; KEINERT, T. M. M. Inovações institucionais participativas: uma abordagem exploratória da produção brasileira em Administração Pública na RAP e no EnAPG (1990-2014). Cadernos EBAPE.BR, v. 14, nº 3, Rio de Janeiro, p. 744-758, 2016.

PERRET B. Indicateurs sociaux et théorie sociale. La Découverte, Revue du MAUSS, $2003 / 1 ; 21$, p. 261 à 275, 2003.

REY-VALETTE H., CHIA E., MATHE S., MICHEL L., NOUGAREDES B., SOULARD C., GUILHENEUF P. Y. Comment analyser la gouvernance territoriale? Géographie, économie, société, $N^{\circ} 161$, pp. 65-89, 2014.

SALGADO, R.; SANTOS, L.; RESENDE, T; SOUZA, W. Cidadania deliberativa e gestão social: revisão sistemática de literatura no Brasil. Cad. EBAPE.BR, v. 17, Edição Especial, Rio de Janeiro, Nov. p. 817-831, 2019.

SIMOULIN V. 2007. La gouvernance: dynamiques discursives, stratégiques et organisationnelles. In PASQUIER R., SIMOULIN V., WEINSTEIN J (dir.), La gouvernance territoriale, $\mathrm{p} 15$ à 32, 2007. 
SILVA, M K, ROCHA, A Rocha. Mediação nas Instituições Participativas:

Articuladores Territoriais e Participação na Política de Desenvolvimento Territorial. Interseções, v. 17 n. 1, p. 136-164, Rio de Janeiro, 2015.

SOUZA, C; CARVALHO, I. Reforma de Estado, Descentralização e Desigualdades.

Revista Lua Nova, $n^{\circ}$ 48. p. 187 -244, 1999.

SOUZA, C. Modernização do Estado e construção de capacidade burocrática para a implementação de políticas federalizadas. Revista de Administração Pública. Rio de Janeiro 51(1): 27-45, jan. - fev. 2017.

TORRE A. Les processos de gouvernance territoriale, l'apport des proximités. GREP, Pour, p. 114 à 122, 2011.

TORRE A., TRAVERSAC J.B. Territorial Governance. Local Development, Springer Verlag, Heidelberg \& N. York, 2011.

TENÓRIO, F. Prefácio. In: PAES DE PAULA, Ana Paula. Por uma nova gestão pública. RJ: Editora FGV, 2005.

VALENCIA, M. La Gestión de la información como instrumento de política de desarrollo rural con enfoque territorial: la experiencia del Ministerio de Desarrollo Agrario de Brasil. In: CLICHE, G. (ed). Territorios en Movimiento. Teseo: Buenos Aires, p. 145-168, 2014.

VALENCIA, M., SABOURIN E., SAYAGO D., BALESTRO M. "Programa de Desenvolvimento Sustentável de Territórios Rurais" in Sabourin E., Grisa C. (coord.), A difusão de políticas brasileiras para a agricultura familiar na América Latina. Porto Alegre, Escritos Editora, p. 89-114, 2018.

VALENCIA, M.; LE COQ, J.F.; FAVARETO, A.; SAMPER, M.; SAENZ-SEGURA, F.; SABOURIN, E., Hacia una nueva generación de políticas públicas para el desarrollo territorial rural en América Latina, Info - Note DTR, Rede PP-Al, RETE, 2019.

VALENCIA, M.; CANIELLO, M.; BARONE, L.; PIRAUX, M.; CALVI, M.; TEIXEIRA, O.; OLIVEIRA, D., Doce años del Programa Desarrollo Sostenible de Territorios Rurales del Ministerio de Desarrollo Agrario del Brasil, in BERDEGUÉ, J.; CHRISTIAN, C.; FAVARETO, A. (orgs.), Quince Años de Desarrollo Territorial Rural en América Latina. Buenos Aires: Teseo, 2020, p. 121 -174.

VEIGA, J. E.; FAVARETO, A.; AZEVEDO, C.; BITTENCOURT, J.; VECCHIATTI, K.; MAGALHÃES, R.; JORGE, R. O Brasil rural precisa de uma estratégia de desenvolvimento. Série textos para discussão, n. 1. Brasília: NEAD/CDR, 2001. 
Marc Piraux. Doutor em agro-economia. Cirad (Centro de cooperação internacional em pesquisa agronômica para o desenvolvimento) -UMR Tetis, INRAE, CIRAD, CNRS, Agroparistech. Montpellier, France. Professor colaborador INEAF UFPA Belém. marc.piraux@cirad.fr

Mireya E. Valencia Perafán. Doutora em Ciências Sociais. Universidade de Brasília (UnB). Professora. Diretora Presidente da Rede Brasileira de Pesquisa e Gestão em Desenvolvimento Territorial-RETE. mireya@unb.br

Marcio Caniello. Doutor em Antropologia. Universidade Federal de Campina Grande (UFCG). Professor Titular de Antropologia e Professor Permanente do Programa de Pós-Graduação em Ciências Sociais (PPGS). marciocaniello@gmail.com

Betty Nogueira Rocha. Doutora em Ciências Sociais em Desenvolvimento Agricultura e Sociedade. Universidade Federal Rural do Rio de Janeiro (UFRRJ). Professora Associada. bettyrocha@ufrrj.br

Como citar: PIRAUX, Marc et al. Avaliar a gestão social na governança territorial: bricolagem, aprendizagem e hibridação na construção do Índice de Gestão Social (IGS). Redes, Santa Cruz do Sul, v. 25, n. 3, p. 1071-1095, sep. 2020. ISSN 1982-6745. doi: https://doi.org/10.17058/redes.v25i3.15233.

\section{CONTRIBUIÇÃO DE CADA AUTOR}

a. Fundamentação teórico-conceitual e problematização: Marc Piraux, Mireya E. Valencia Perafán, Marcio Caniello, Betty Nogueira Rocha

b. Pesquisa de dados e análise estatística: Marc Piraux, Mireya E. Valencia Perafán, Marcio Caniello, Betty Nogueira Rocha

c. Elaboração de figuras e tabelas: Marc Piraux, Mireya E. Valencia Perafán, Marcio Caniello, Betty Nogueira Rocha

d. Fotos: não se aplica

e. Elaboração e redação do texto: Marc Piraux, Mireya E. Valencia Perafán, Marcio Caniello, Betty Nogueira Rocha

f. Seleção das referências bibliográficas: Marc Piraux, Mireya E. Valencia Perafán, Marcio Caniello, Betty Nogueira Rocha

Fontes de financiamento: Ministério do Desenvolvimento Agrário e CNPq. 